\title{
Long-term follow-up review of patients who underwent laminectomy for lumbar stenosis: a prospective study
}

\section{Manucher J. Javid, M.D., and Eldad J. Hadar, M.D.}

Department of Neurological Surgery, University of Wisconsin Hospital and Clinics, Madison, Wisconsin

Object. Decompressive laminectomy for stenosis is the most common operation performed on the lumbar spine in older patients. This prospective study was designed to evaluate long-term results in patients with symptomatic lumbar stenosis.

Methods. Between January 1984 and January 1995, 170 patients underwent surgery for lumbar stenosis (86 patients), lumbar stenosis and herniated disc (61 patients), or lateral recess stenosis (23 patients). The male/female ratio for each group was 43:43, 39:22, and 14:9, respectively. The average age for all groups was 61.4 years. For patients with lumbar stenosis, the success rate was $88.1 \%$ at 6 weeks and $86.7 \%$ at 6 months. For patients with lumbar stenosis and herniated disc, the success rate was $80 \%$ at 6 weeks and $77.6 \%$ at 6 months, with no statistically significant difference between the two groups. For patients with lateral recess stenosis, the success rate was $58.7 \%$ at 6 weeks and $63.6 \%$ at 6 months; however, the sample was not large enough to be statistically significant. One year after surgery a questionnaire was sent to all patients; $163(95.9 \%)$ responded. The success rate in patients with stenosis had declined to $69.6 \%$, which was significant $(\mathrm{p}=0.012)$; the rate for patients with stenosis and herniated disc was $77.2 \%$; and that for lateral recess stenosis was $65.2 \%$. Another follow-up questionnaire was sent to patients 1 to 11 years after surgery (average 5.1 years); 146 patients $(85.9 \%)$ responded, $10(5.9 \%)$ were deceased, and $14(8.2 \%)$ were lost to follow-up review. At 1 to 11 years the success rate was $70.8 \%$ for patients with stenosis, $66.6 \%$ for those with stenosis and herniated disc, and $63.6 \%$ for those with lateral recess stenosis. Eleven patients who underwent reoperation were included in the group of patients whose surgeries proved unsuccessful, regardless of their ultimate outcome. There was no statistically significant difference in outcome between 1 year and 1 to 11 years with respect to stenosis, stenosis with herniated disc, and lateral recess stenosis.

Conclusions. In conclusion, long-term improvement after laminectomy was maintained in two-thirds of these patients.

Key Words * lumbar stenosis * spinal stenosis * laminectomy * prospective study * outcome

Decompressive laminectomy for lumbar stenosis is the most common operation performed in the lumbar spine in older-aged patients. This is especially due to the increasing recognition of this condition and the availability of noninvasive axial imaging. From 1979 to 1992, surgery for spinal stenosis increased eightfold in the United States. This rate can be expected to increase as the population ages.[4] 
There have been numerous retrospective studies in which the results of surgery with and without fusion have been reported. Turner, et al.,[29] conducted a metaanalysis of 74 journal articles, published from 1966 to 1990 , that met the inclusion criteria. On average, 64\% of patients treated surgically for lumbar stenosis had a good to excellent outcome. After reviewing 47 articles in which patient outcome after lumbar spinal fusion was reported, the same authors[28] found no advantage to using fusion. On average, $68 \%$ of patients achieved a satisfactory outcome after fusion; however, the range was wide (16-95\%) and the satisfactory outcome rate was lower in prospective than in retrospective studies.

By searching a computer on-line database (Medline; National Library of Medicine, Bethesda, MD) for English-language articles published from 1962 through 1996 containing data on outcomes of surgery, we found only seven prospective studies with follow-up times ranging from 6 months to 5 years and successful outcome rates ranging from 52 to $78 \%$ (Table 1).

\begin{tabular}{|lccc|}
\hline \multicolumn{5}{|c|}{ TABLE 1 } \\
RESULTS OF LAMNECTOMES PERFORMED FOR LUMEAR STENOSIS: \\
PROSPECTME STUDIES
\end{tabular}

The purpose of this prospective study was to evaluate long-term outcome in patients who underwent laminectomy for symptomatic lumbar stenosis. The duration of follow up in these cases ranged from 1 to 11 years.

\section{CLINICAL MATERIAL AND METHODS}

In January 1984 the senior author (M.J.J.) began a prospective study of all patients who were to undergo decompressive laminectomy for stenosis confirmed by computerized tomography (CT) myelography scanning and/or magnetic resonance (MR) imaging. Patients were asked to participate in this evaluation of surgical results by undergoing postoperative follow-up examination at 6 weeks and 6 months and by filling out a questionnaire at 1 year and another questionnaire later for evaluation of long-term results. Patients who had undergone previous surgery for stenosis were excluded. During a period lasting 11 years, 170 patients underwent surgery performed by the senior author. Of these patients, 83 had lumbar stenosis, 61 patients had lumbar stenosis with a herniated disc, and 23 patients had lateral recess stenosis. The patients' gender, age, height, and weight are shown in Table 2. The presence of obesity was calculated according to criteria described in the Second National Health and Examination Survey.[30] By using these criteria, obesity exists if the patient's weight exceeds the 85th percentile for individuals with the same height. This cut-off point constitutes a body mass index of 27.8 in males and 27.3 in females. The body mass index is calculated by dividing the weight in kilograms by the height squared in meters. According to these criteria, $34.5 \%$ of the patients who had stenosis, $(36.3 \%$ of the men and $32.5 \%$ of the women), $41.3 \%$ of the patients who had stenosis and a herniated disc $(33.3 \%$ of the men and $54.5 \%$ of 
the women), and $30.4 \%$ of the patients who had lateral recess stenosis ( $21.4 \%$ of the men and $44.4 \%$ of the women) were obese.

\begin{tabular}{|c|c|c|c|}
\hline \multicolumn{4}{|c|}{$\begin{array}{c}\text { TABLE } 2 \\
\text { SUMMRY OF PHYSCAL CHARACTERISTKS OF } 170 \text { PATIENTS UNDERGONG } \\
\text { LAMNECTOMY FOR LUMBAR STENOSIS }\end{array}$} \\
\hline Characteristic & $\begin{array}{c}\text { Stenosis } \\
\text { (86 patients) }\end{array}$ & $\begin{array}{c}\text { Stencsis \& } \\
\text { Hemiat edDisc } \\
\text { (61 pati ents) }\end{array}$ & $\begin{array}{c}\text { Lateral Recess } \\
\text { Stencosis } \\
\text { (23 pa.ti ents) }\end{array}$ \\
\hline \multicolumn{4}{|l|}{$\operatorname{sen}$} \\
\hline $\begin{array}{l}\text { male } \\
\text { female }\end{array}$ & $\begin{array}{l}43(50 \%) \\
43(50 \%)\end{array}$ & $\begin{array}{l}39(63.9 \%) \\
22(36.1 \%)\end{array}$ & $\begin{array}{l}14(61 \%) \\
9(39 \%)\end{array}$ \\
\hline \multicolumn{4}{|l|}{ age (yrs) } \\
\hline $\begin{array}{l}\text { range } \\
\text { awerage } \\
\text { height (om) }\end{array}$ & $\begin{array}{c}27-89 \\
64.7\end{array}$ & $\begin{array}{c}23-82 \\
59.1\end{array}$ & $\begin{array}{c}25-79 \\
53.6\end{array}$ \\
\hline $\begin{array}{l}\text { range } \\
\text { average }\end{array}$ & $\begin{array}{c}144.8-185.4 \\
169.4\end{array}$ & $\begin{array}{c}154.9-195.6 \\
173.2\end{array}$ & $\begin{array}{c}157.5-193.0 \\
173.5\end{array}$ \\
\hline \multicolumn{4}{|l|}{ meight (kg) } \\
\hline $\begin{array}{l}\text { range } \\
\text { average }\end{array}$ & $\begin{array}{c}48.6-118.2 \\
81.4\end{array}$ & $\begin{array}{c}50.9-127.3 \\
84.5\end{array}$ & $\begin{array}{c}67.7-101.8 \\
78.5\end{array}$ \\
\hline
\end{tabular}

\section{Patients' Symptoms}

Symptoms associated with lumbar stenosis included: back pain in $96.3 \%$ of patients, average duration 42 months; leg pain in $97.5 \%$ of patients, average duration 27 months; paresthesias in $79.5 \%$ of patients; and walking difficulty in $75.7 \%$ of patients. Symptoms associated with lumbar stenosis with herniated disc included: back pain in $100 \%$ of patients, average duration 79 months; leg pain in $98.3 \%$ of patients, average duration 30.8 months; paresthesias in $73.1 \%$ of patients; and walking difficulty in $57 \%$ of patients. Symptoms associated with lateral recess stenosis included: back pain in $100 \%$ of patients, average duration 38 months; leg pain in $95.7 \%$ of patients, average duration 21.5 months; paresthesias in $89.5 \%$ of patients; and walking difficulty in $55 \%$ of patients.

\section{Clinical Signs}

Abnormal signs found in patients with lumbar stenosis were: positive straight leg raising in 55\%; sensory impairment in 51.2\%; motor deficit in $35.7 \%$; and reflex changes in $51.8 \%$ of the patients. Signs in patients who had lumbar stenosis and herniated disc included: positive straight leg raising in $84.2 \%$; sensory impairment in 53.6\%; motor deficit in $41.7 \%$; and reflex changes in $36.7 \%$. The signs apparent in patients who had lateral recess stenosis were: positive straight leg raising in $90 \%$; sensory impairment in $63.6 \%$; motor deficit in $52.2 \%$; and reflex changes in $34.7 \%$.

\section{Diagnostic Studies}

Initially, our choice of diagnostic study was CT myelography scanning, which was considered to be the gold standard at that time. With the advent of MR imaging, this procedure was used in the majority of patients, and CT myelography scanning was reserved for use when additional information was deemed of potential value. In patients who had lumbar stenosis, the percentages of these procedures that were used were: CT myelography scanning, 53\%; MR imaging, 21.7\%; CT scanning and MR imaging, 19.3\%; and CT scanning, $6 \%$. In patients with lumbar stenosis and herniated disc the percentages were: CT myelography scanning, 58\%; MR imaging, 23\%; CT myelography scanning and MR imaging, 17.5\%; 
and CT scanning, $1.5 \%$. In patients with lateral recess stenosis the percentages were: CT myelography scanning, $78.3 \%$; and CT myelography scanning and MR imaging, 21.7\%.

\section{Surgical Technique}

Bilateral laminectomy and medial facetectomy were performed in patients who had lumbar stenosis and in those who had lumbar stenosis with herniated disc. Fusion was performed in nine of 86 patients who had lumbar stenosis. In six of these patients, fusion was performed during the original operation because of the coexistence of degenerative spondylolisthesis (four patients with instrumentation and two patients without instrumentation). In three patients fusion was performed during the second operation (two patients with instrumentation and one patient without instrumentation). The average number of levels included in the laminectomy was 2.5 for lumbar stenosis and 2.16 for lumbar stenosis and herniated disc. The average length of stay was 6.5 days for patients with lumbar stenosis and 5.7 days for patients with lumbar stenosis and herniated disc.

\section{Complications of Surgery}

In one patient with lumbar stenosis, a dural tear occurred during the operation; this was sutured at the time of surgery. One patient with lumbar stenosis and herniated disc also suffered a dural tear that was sutured, and two patients had superficial infection, which was treated successfully in both patients.

\section{Follow-Up Evaluation}

The patients were examined at 6 weeks and 6 months postoperatively. A follow-up questionnaire was sent to the patients for a 1-year evaluation. In January 1996 an additional questionnaire was sent to all patients for a 1- to 11-year follow-up evaluation. The questionnaires were filled out and returned by $85.9 \%$ of the patients; $5.8 \%$ had died from unrelated diseases and $8.2 \%$ were lost to follow up.

\section{Statistical Analysis}

Percentages were compared using Fisher's exact two-tailed test, and times were compared using Wilcoxon's ranks sums test. Commercially available statistical software (SAS Institute Inc., Cary, NC) was used to perform all analyses.

\section{RESULTS}

\section{Results at 6 Weeks}

Successful results of surgery were achieved in $88.1 \%$ of the patients with lumbar stenosis, $80 \%$ of the patients with lumbar stenosis and disc herniation, and $58.7 \%$ of the patients with lateral recess stenosis. There was no statistically significant difference between results in patients with stenosis and those with stenosis with herniated disc. The success rate for patients with lateral recess stenosis was much lower and suggests a difference; however, the sample was not large enough to be statistically significant (Fig. 1 upper). We have no explanation for this. Hypothetically, one may postulate that in lateral recess stenosis the nerve root may have experienced bone compression for a longer period of time, which may require more healing time for recovery. In some instances the root manipulation may be considerably more. It is also possible that a slight slippage caused the instability. 

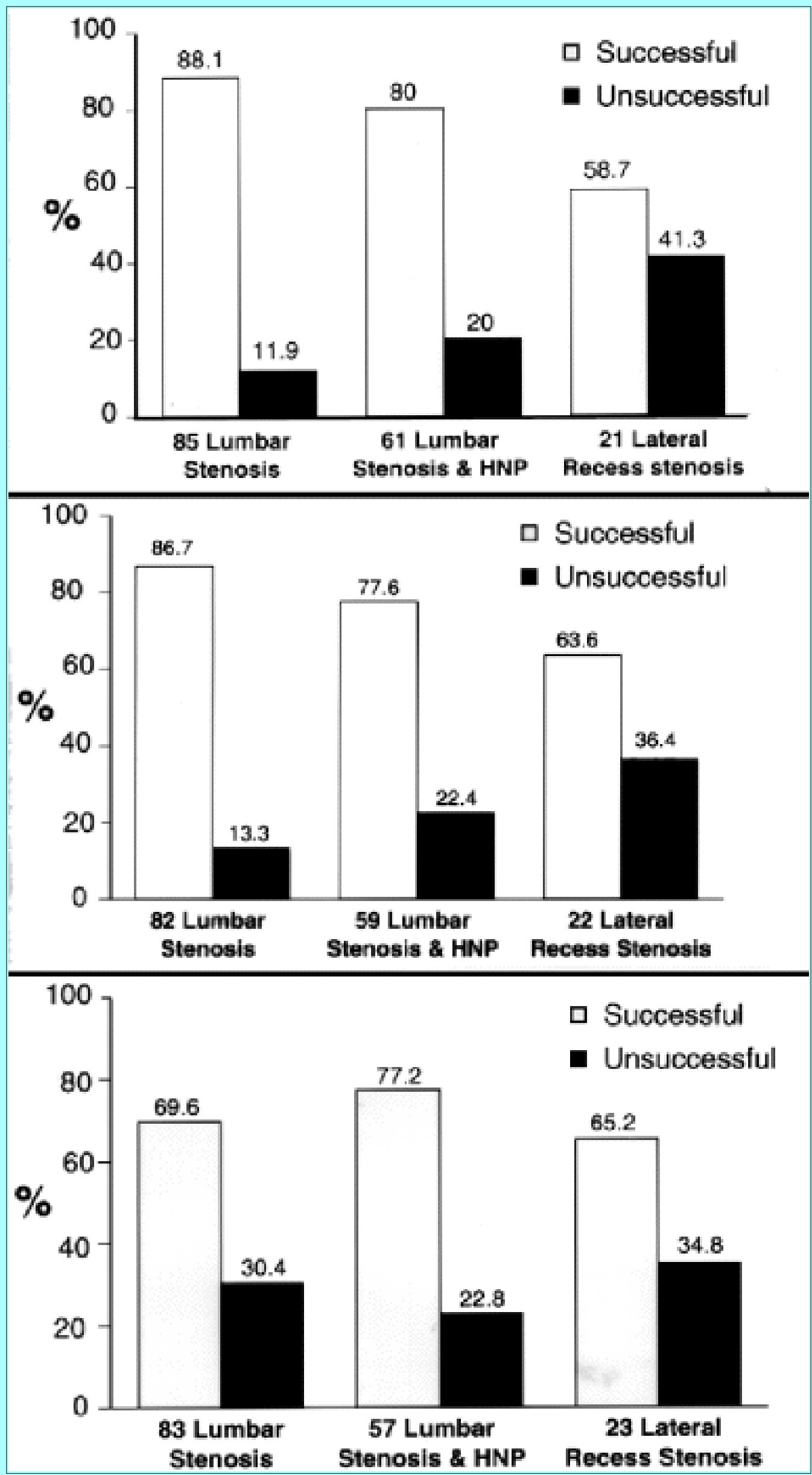

Fig. 1. Bar graphs. Upper: Overall results 6 weeks after laminectomy. Center: Overall 
results 6 months after laminectomy. Lower: Overall results 1 year after laminectomy. HNP $=$ herniated disk.

\section{Results at 6 Months}

Successful results of surgery were achieved in $86.7 \%$ of patients with lumbar stenosis, $77.6 \%$ of patients with lumbar stenosis with herniated disc, and $63.6 \%$ of patients with lateral recess stenosis (Fig. 1 center).

\section{Results at 1 Year}

Successful results of surgery for lumbar stenosis declined to $69.6 \%$ by 1 year postoperatively. This was statistically significant $(\mathrm{p}=0.012)$ for cases of lumbar stenosis with disc herniation $(77.2 \%)$ and cases of lateral recess stenosis $(65.2 \%)$ (Fig. 1 lower). There was no statistically significant difference at 1 year in the results between men and women or between obese and nonobese patients.

\section{Results at Last Follow Up}

The results of the last questionnaire sent at 1 to 11 years (average 5.1 years) showed the success rates for surgical correction to be $70.8 \%$ for stenosis, $66.6 \%$ for stenosis and herniated disc, and $63.6 \%$ for lateral recess stenosis (Fig. 2). There were no statistically significant differences between the results reported at 1 year and those reported at the last follow up (1-11 years) in patients with stenosis alone or those with stenosis and herniated disc.

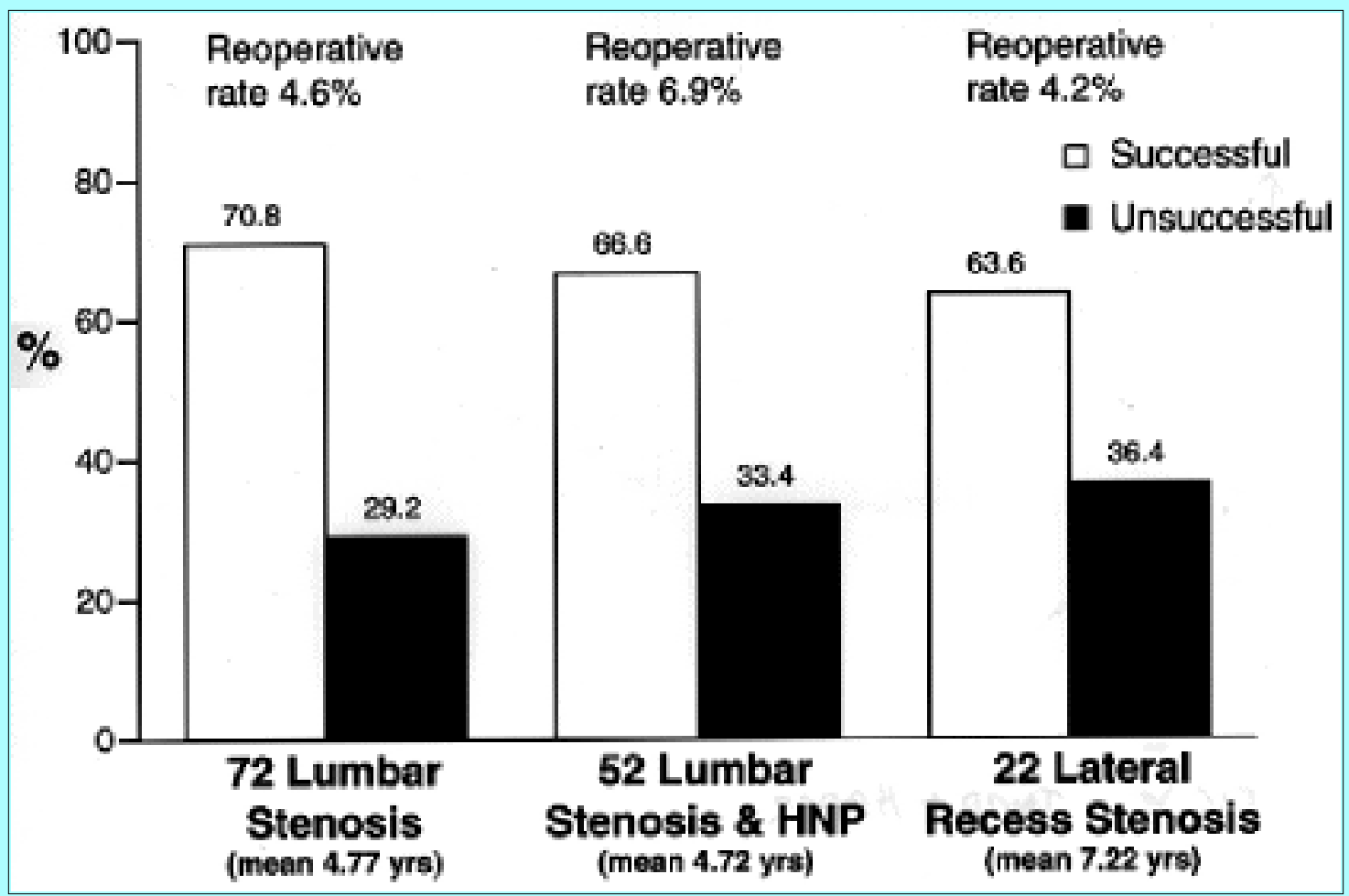

Fig. 2. Bar graph depicting overall results 1 to 11 years after laminectomy.

The results for six patients who underwent lumbar fusion during their original surgery for lumbar stenosis at 1 year were successful in five patients and treatment failure in one. The results for three patients who underwent fusion during the second operation were successful in two patients and treatment failure in one patient. At 1 to 11 years, the results in both groups were successful in five patients and failure in three patients; one patient died of an unrelated cause. 


\section{Additional Treatment After Surgery}

Of 72 patients who were surgically treated for lumbar stenosis, 29 were taking analgesic drugs either occasionally or regularly and four of these patients were taking Tylenol with codeine. Of 52 patients who were surgically treated for lumbar stenosis and herniated disc, 14 patients were taking analgesic medications and two patients were receiving codeine. Of 22 patients who were surgically treated for lateral recess stenosis, eight patients were taking analgesic medications and two patients were taking codeine in addition.

Of the 170 patients who underwent surgery, 11 patients underwent a second operation. Four of these patients had lumbar stenosis with an average interval of 41.3 months between the two operations. At surgery, two patients had stenosis above the previous laminectomy level. Two needed decompressive laminectomy below the level previously treated as well as additional bone removal at levels of previous laminectomy. The results showed success in two patients and treatment failure in two patients.

Five patients whose original operation was for lumbar stenosis and herniated disc underwent reoperation, with an average interval of 34.9 months between the two procedures. At surgery, four of these patients had recurrent disc herniation and one patient had a herniated disc at another level. Two patients had successful results and three had treatment failures.

Two patients who underwent surgery for lateral recess stenosis required a second operation, with an average interval of 27 months between the procedures. At surgery, one patient had an extruded disc and one patient had scar and stenosis. Both patients had persistent symptoms including pain.

\section{Patients' Assessments of Results of Surgery at 1 to 11 Years}

The percentages of patients reporting improvements in back pain, leg pain, paresthesias, and walking are shown in Fig. 3.

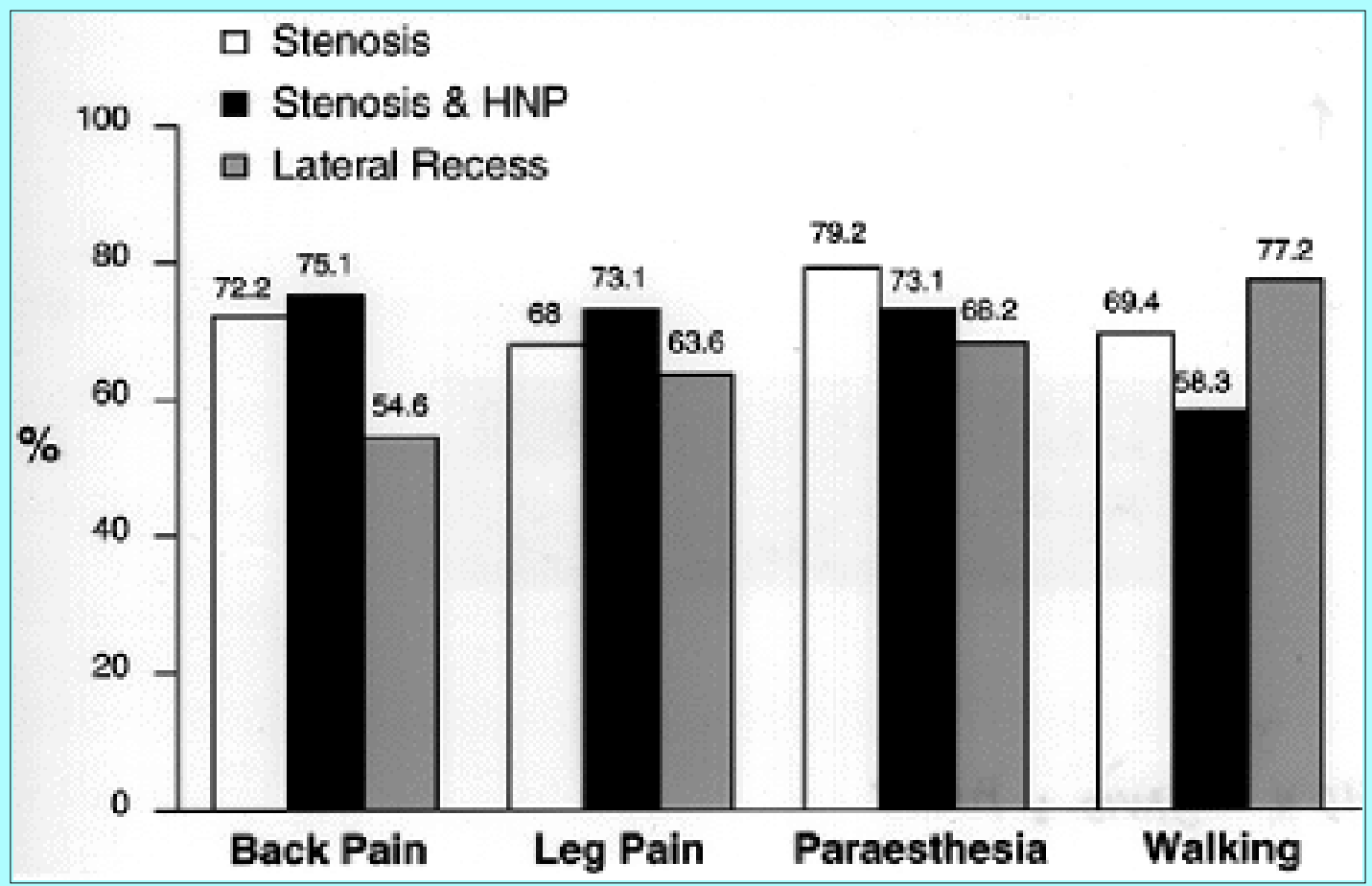

Fig. 3. Bar graph showing the percentages of improvement in symptoms 1 to 11 years after laminectomy in the three groups of patients. 
In their responses to the questionnaire obtained at 1 to 11 years, patients rated how often they experienced back pain, leg pain, and paresthesias according to the following scale: none, rarely, sometimes, most times, and constant. The results are shown in Fig. 4. Patients with lumbar stenosis reported an overall asymptomatic rate of $18 \%$ (Fig. 4 upper); the overall asymptomatic rates in patients with lumbar stenosis and herniated disc and in patients with lateral recess stenosis were $21 \%$ (Fig. 4 center) and 27\% (Fig. 4 lower), respectively.

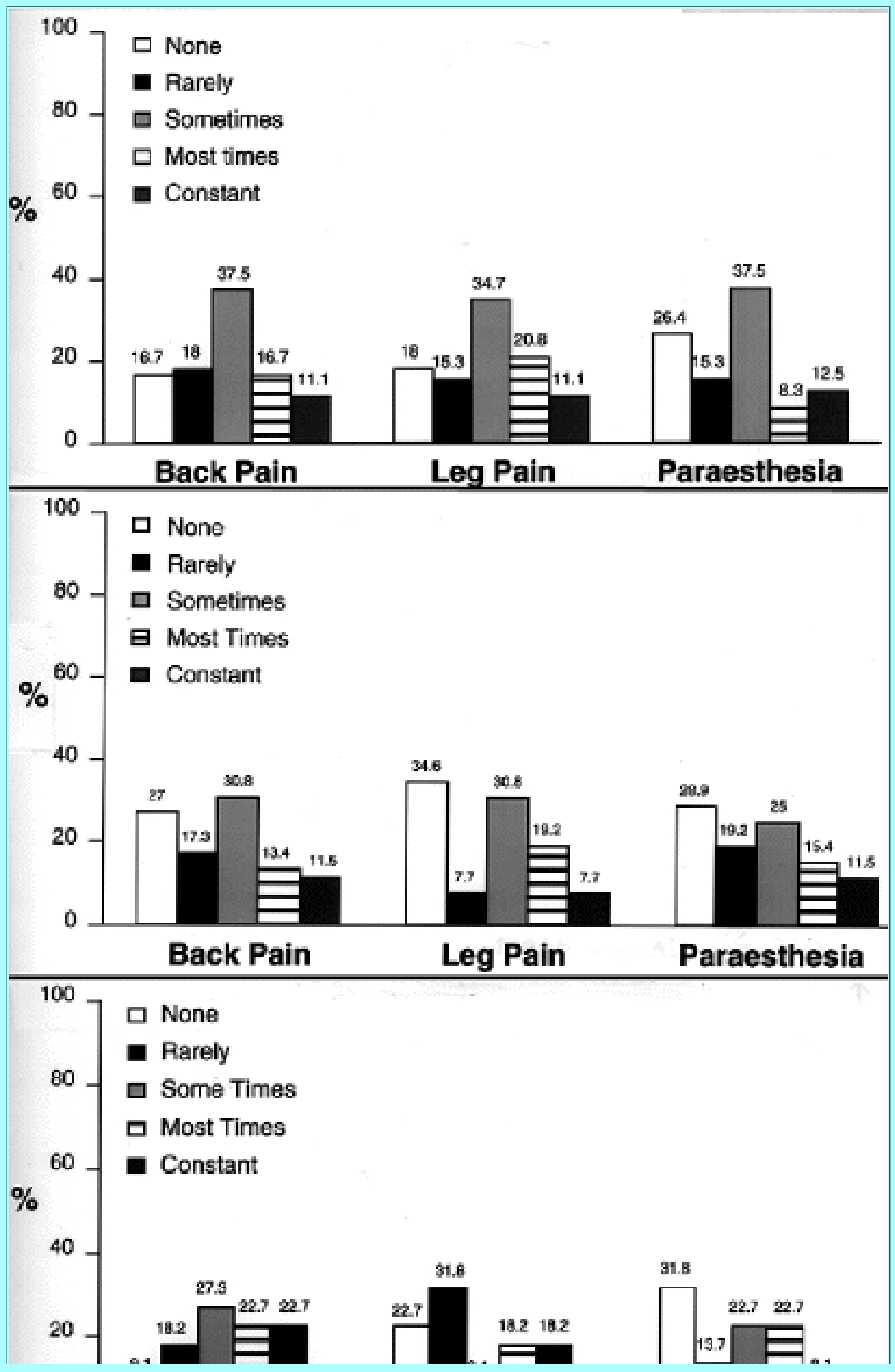




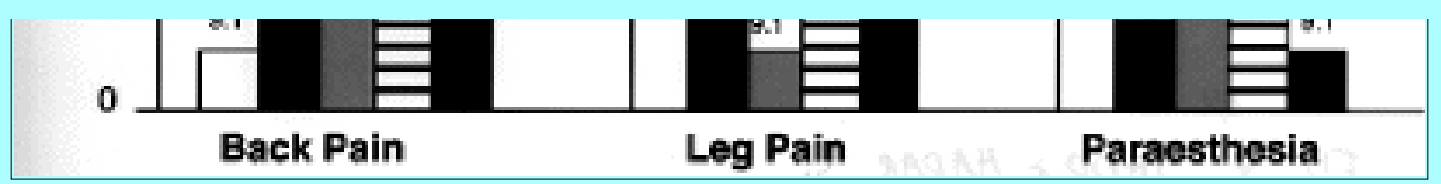

Fig. 4. Bar graphs depicting patients' perceptions of improvement in symptoms. Upper: Patients with lumbar stenosis. Center: Patients with lumbar stenosis and herniated disc. Lower: Patients with lateral recess stenosis.

Patients judged their improvement in walking at 1 to 11 years according to whether their walking was much better, somewhat better, no different, somewhat worse, or much worse. The results for each group of patients are shown in Fig. 5.

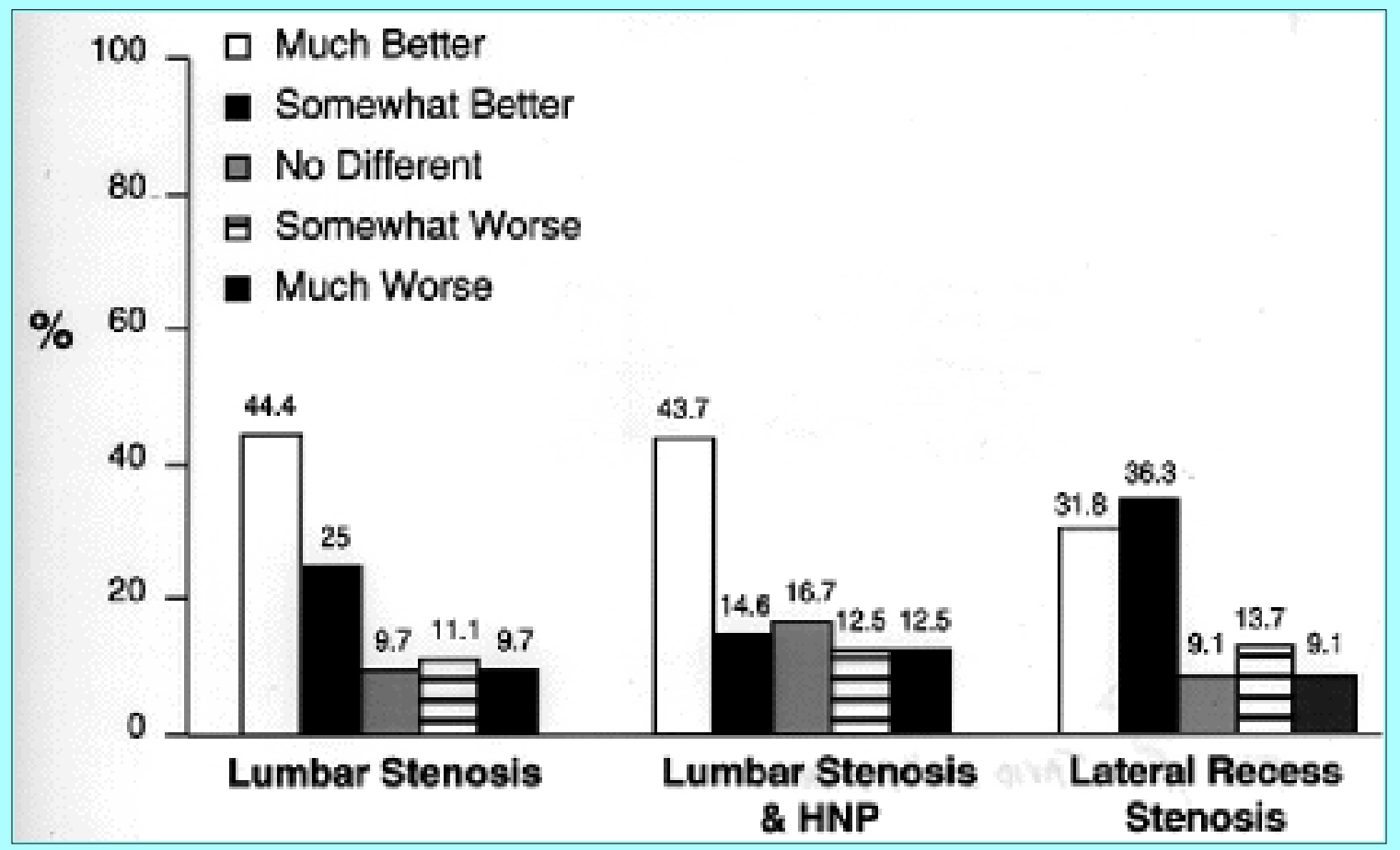

Fig. 5. Bar graph showing patients' perception of improvement in walking in the three groups.

\section{Pre- and Postoperative Employment}

The incidence of employment postoperatively in patients who had been employed prior to surgery was as follows: $56.5 \%$ of patients with lumbar stenosis, $74 \%$ of patients with lumbar stenosis and herniated disc, and $42.8 \%$ of patients who were surgically treated for lateral recess stenosis.

\section{Patient Satisfaction}

Figure 6 shows the response of patients to the question of whether, in retrospect, they would still choose surgery. 


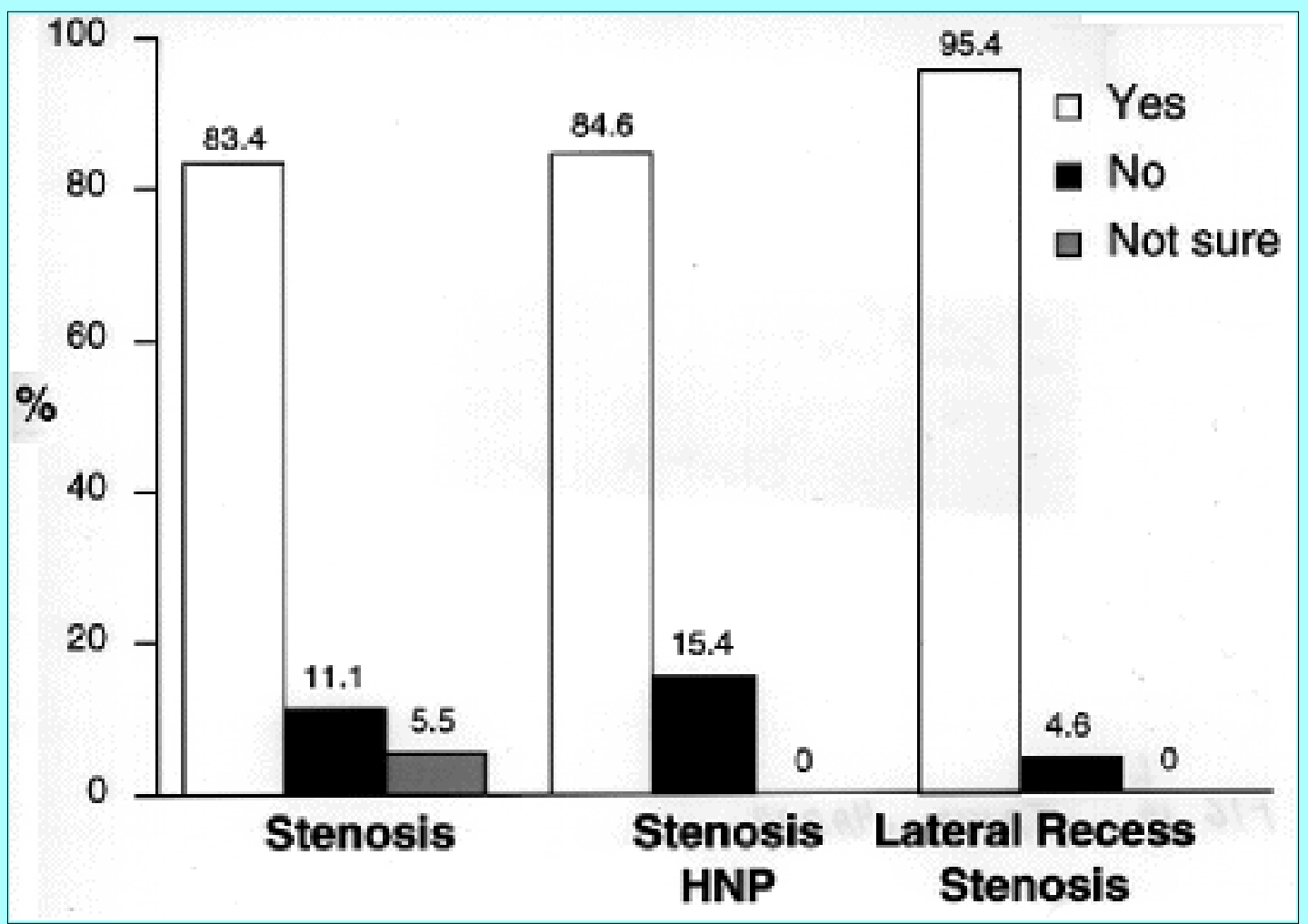

Fig. 6. Bar graph showing percentages of patients who, retrospectively, would still choose surgery.

\section{DISCUSSION}

\section{Review of the Literature}

In 1892 Von Bechtrew[33] reported on patients who had rigidity of the vertebral column and nerve root symptoms. In 1893 Lane[20] reported on a patient who had cauda equina syndrome with difficulty in walking and who underwent L-5 decompressive laminectomy for lumbar stenosis. In 1900 Sachs and Frankel[25] performed a two-level laminectomy in a patient who had back pain and neurogenic claudication, relieving the patient's leg pain. In 1911 Bailey and Casamajor[3] published a paper on osteoarthritis of the spine and compression of the spinal cord and its roots. In the same year Dejerine[6] coined the term "intermittent claudication of the spinal cord." Three years later Kennedy and colleagues[16] reported on 22 patients who had undergone surgery for lumbar stenosis. In 1925 Parker and Adson[23] reported on compression of the spinal canal and its roots by hypertrophic osteoarthritis and emphasized that a complete laminectomy should be performed to obtain good results. A number of publications regarding surgery for stenosis had been distributed; however, it was in 1949 that Verbiest,[32] a Dutch neurosurgeon, introduced the concept of spinal stenosis and coined the term "stenosis of the vertebral canal," and in 1954 he wrote his landmark paper[31] on this subject, which brought stenosis to the attention of neurological and orthopedic surgeons. Kirkaldy-Willis and colleagues[18,19] made further contributions to knowledge about the pathology and pathogenesis of lumbar spondylosis and stenosis. Extensive literature on this subject has been published since Verbiest's contribution, the vast majority of which pertains to retrospective studies including a short follow up of patients; the patients' opinions were incorporated into the assessment of outcome in only some of these studies.[11,12,14,27,34]

Lateral recess stenosis was reported in two patients by Schlesinger in 1955,[26] in 12 patients by Epstein, 
et al.,[8] in 1972, and in 16 patients by Ciric, et al.,[5] in 1980. It is important to keep in mind the coexistence of central, lateral recess stenosis and herniated disc to avoid failure.

As a result of advances in imaging techniques, CT scanning with or without myelography, and MR imaging, there has been a marked increase in the diagnosis of, and subsequent surgery for, lumbar stenosis.[17]

The majority of patients with lumbar stenosis should be treated conservatively because the episodes of back and leg pain will improve with time. Furthermore, Katz and coworkers[15] have shown that initial improvement in symptoms worsens over time after decompressive laminectomy.

The Maine study[2] showed that among the 148 patients with lumbar stenosis, the success rate at 1 year for patients who had undergone surgery was substantially better than for those who had nonsurgical treatment. Eighty-one patients were treated surgically and 67 patients were treated nonsurgically. Overall, the success rate was $69 \%$ for surgical patients compared with $36 \%$ for nonsurgical patients. The authors of the Maine report stated that, although there was a greater chance of improvement after surgery at 1 year, nonsurgically treated patients gradually improved.

As a palliative, epidural steroid injection is of limited value. However, in elderly patients when surgery carries greater risk it may be considered.[24]

In the majority of patients who are candidates for decompressive laminectomy, fusion is not indicated unless the patient has significant instability because of disc degeneration and facet collapse. There is no definite evidence that adding fusion improves the success rate. Furthermore, fusion increases the costs of treatment and morbidity and mortality rates.[4,7] Pappas and Sonntag[22] reported on 206 patients who underwent decompressive laminectomy for lumbar stenosis with a mean follow-up time of 28 months; six patients $(2.9 \%)$ needed a subsequent operation for fusion. In the present series, of 80 patients with lumbar stenosis who underwent decompressive laminectomy with a mean follow up of 61 months, three patients $(3.8 \%)$ needed a subsequent operation for fusion.

On reviewing 47 articles, Turner and associates[29] found four studies in which surgery was compared with and without fusion; no advantage for fusion was found in three of those studies. On average, $68 \%$ of patients had a satisfactory outcome after fusion but the range was wide (16-95\%).

Fischgrund, et al.,[9] recently published a report on a prospective randomized 2-year follow-up study of 76 patients who had degenerative lumbar spondylolisthesis with lumbar stenosis. When comparing decompressive laminectomy with and without spinal instrumentation, these authors showed a success rate of $76 \%$ in patients in whom instrumentation was placed and a rate of $85 \%$ in those in whom no instrumentation was placed $(\mathrm{p}=0.45)$. Successful arthrodesis occurred in $82 \%$ of cases that involved instrumentation compared with $45 \%$ of cases that did not $(p=0.0015)$. Overall, successful fusion did not influence patient outcome. The authors concluded that the use of pedicle screws may lead to a higher fusion rate, but not to clinical improvement. Following up that well-conducted study, it is important that the patients be evaluated over the long term to determine whether the clinical improvements shown for both groups at 2 years after the operation will continue.

\section{The Need for Reoperation}

In a report by Tuite, et al.,[27] 15\% of 119 patients who had undergone laminectomy needed repeated surgery; none of these patients required fusion. Jönsson and colleagues[13] found a reoperation rate of 
$18 \%$ within 5 years after surgery. On reviewing articles, Turner and associates[29] found reoperation rates ranging from 0 to $21 \%$ (mean $8 \%$ ), but believed this was likely to be an underestimate because not all repeated surgeries may have been reported. In our series of 170 patients, 11 patients, $6.5 \%$ overall (four with lumbar stenosis, five with lumbar stenosis and herniated disc, and two with lateral recess stenosis), required a second operation during the period of study (1-11 years, mean 5.1 years). This included three $(3.8 \%)$ of 80 patients in the lumbar stenosis group who had undergone decompressive laminectomy and required fusion because of instability of the lumbar spine.

\section{Comorbidities in Patients}

In the 86 patients with lumbar stenosis, six patients had coexistent spondylolisthesis and underwent fusion with success in five patients and treatment failure in one patient. One patient with a diagnosis of cardiac problems, one patient with alcoholism, one patient with a bleeding disorder, and one with a history of Guillain-Barré syndrome all did well. The patient who had a history of alcoholism continued to do well but died of pulmonary cancer 39 months after surgery. Three patients, one with diabetes, one with Parkinson's disease and agitated depression, and one with a borderline personality who had attempted suicide, had a failed result.

Among the 61 patients who had lumbar stenosis with herniated disc, four had cardiac problems, of whom one had successful results, and one patient had a successful result at 1 year but required bypass 20 months postoperatively; at the time of the latter evaluation the last case was listed in the unsuccessful category. Two patients who initially had good results died postoperatively, one 4 months after surgery and one 10 months after surgery, from cardiac complications. One patient who had done well after laminectomy died 1 year after surgery for prostate cancer.

Among the 23 patients who had lateral recess stenosis, one patient had undergone a mastectomy 10 years before surgery with no evidence of metastasis and one patient had been successfully treated for Hodgkins' disease. Both have maintained their successful result since surgery.

\section{Success of Surgical Intervention}

The success rate of surgical intervention for lumbar stenosis has been reported to range from 26 to 100\%.[1] The metaanalysis performed by Turner and associates[29] showed a success rate of 64\%. To our knowledge there were seven prospective studies published between 1983 and 1997 (Table 1) on a total of 983 patients with an average success rate of $67.8 \%$. The present prospective study of 170 patients with follow up from 1 to 11 years (average 5.1 years) showed the success rate of decompressive laminectomy to be $70.8 \%$ for lumbar stenosis, $66.6 \%$ for lumbar stenosis and herniated lumbar disc, and $63.6 \%$ for lateral recess stenosis. Although improvement was achieved overall in $65 \%$ of patients, $88 \%$ of patients indicated that, in retrospect, they would still have undergone surgery.

Multicenter randomized studies are needed to compare the surgical and nonsurgical treatment of spinal stenosis. Additional randomized studies with long-term patient follow up are needed to compare decompressive laminectomy with and without fusion.

\section{CONCLUSIONS}

The long-term results of decompressive laminectomy for lumbar stenosis in this prospective study, as well as in previous studies and in metaanalyses of large numbers of studies, demonstrate that the successful short-term results of surgery are not maintained in a substantial percentage of patients. In 
discussing alternative treatments, conservative treatment compared with surgery, and risks and complications of surgery, it is important to emphasize that the long-term efficacy of laminectomy is maintained in only two-thirds of patients.

\section{Editor's Comment}

The Editor notes that Dr. Manucher Javid's first published article appeared in the Journal of Neurosurgery in 1952. Forty-six years later, Dr. Javid is retiring and he has chosen to publish this article, his last, in the Journal. We congratulate him on his long and productive career.

John A. Jane, M.D., Ph.D.

Editor

\section{References}

1. Airaksinen D, Herno A, Turunen V, et al: Surgical outcome of 438 patients treated surgically for lumbar spinal stenosis. Spine 22:2278-2282, 1997

2. Atlas SJ, Deyo RA, Keller RB, et al: The Maine Lumbar Spine Study, Part III. 1-year outcomes of surgical and nonsurgical management of lumbar spinal stenosis. Spine 21:1787-1795, 1996

3. Bailey P, Casamajor L: Osteo-arthritis of the spine as a cause of compression of the spinal cord and its roots: with report of five cases. J Nerv Ment Dis 38:588-609, 1911

4. Ciol MA, Deyo RA, Howell E, et al: An assessment of surgery for spinal stenosis: time trends, geographic variations, complications, and reoperations. J Am Geriatr Soc 44:285-290, 1996

5. Ciric I, Mikhael M, Tarkington JA, et al: The lateral recess syndrome. A variant of spinal stenosis. J Neurosurg 53:433-443, 1980

6. Dejerine: La claudration intermittente de la moelle épinière. Press Med 19:981-984, 1911

7. Deyo RA, Ciol MA, Cherkin DC, et al: Lumbar spinal fusion. A cohort study of complications, reoperations, and resource use in Medicare population. Spine 18:1463-1470, 1993

8. Epstein JA, Epstein BS, Rosenthal AD, et al: Sciatica caused by nerve root entrapment in the lateral recess: the superior facet syndrome. J Neurosurg 36:584-589, 1972

9. Fischgrund JS, Mackay M, Herkowitz HN, et al: Degenerative lumbar spondylolisthesis with spinal stenosis: a prospective randomized study comparing decompressive laminectomy and arthrodesis with and without spinal instrumentation. Spine 22:2807-2812, 1997

10. Grob D, Humke T, Dvorak J: Degenerative lumbar spinal stenosis. Decompression with and without arthrodesis. J Bone Joint Surg (Am) 77:1036-1041, 1995

11. Hall S, Bartleson JD, Onofrio BM, et al: Lumbar spinal stenosis: clinical features, diagnostic procedures and results of surgical treatment in 68 patients. Ann Intern Med 103:271-275, 1985

12. Johnsson KE, Willner S, Johnsson K: Postoperative instability after decompression for lumbar spinal stenosis. Spine 11:107-110, 1986 
13. Jönsson B, Annertz M, Sjoberg C, et al: A prospective and consecutive study of surgically treated lumbar spinal stenosis. Part II: Five year follow-up by an independent observer. Spine 22:2938-2944, 1997

14. Katz JN, Lipson SJ, Brick GW, et al: Clinical correlates of patient satisfaction after laminectomy for degenerative lumbar spinal stenosis. Spine 20:1155-1160, 1995

15. Katz JN, Lipson SJ, Larson MG, et al: The outcome of decompressive laminectomy for degenerative lumbar stenosis. J Bone Joint Surg (Am) 73:809-816, 1991

16. Kennedy F, Elsberg CA, Lambert CI: A peculiar and undescribed disease of the nerves of the cauda equina. Am J Med Sci 147:645-667, 1914

17. Kent DL, Haynor DR, Larson EB, et al: Diagnosis of lumbar spinal stenosis in adults: a meta-analysis of the accuracy of CT, MR and myelography. AJR 158:1135-1144, 1992

18. Kirkaldy-Willis WH, Paine KWE, Cauchoix J, et al: Lumbar spinal stenosis. Clin Orthop 99:30-50, 1974

19. Kirkaldy-Willis WH, Wedge JM, Young-Hing K, et al: Pathology and pathogenesis of lumbar spondylosis and stenosis. Spine 3:319-328, 1978

20. Lane WA: Case of spondylolisthesis associated with progressive paraplegia: laminectomy. Lancet 1:991-992, 1893

21. Larequi-Lauber T, Vader JP, Burnand B, et al: Appropriateness of indications for surgery of lumbar disc hernia and spinal stenosis. Spine 22:203-209, 1997

22. Pappas CTE, Sonntag VKH: Lumbar stenosis in the elderly. Neurosurg Q 4:102-112, 1994

23. Parker HL, Adson AW: Compression of the spinal canal and its roots by hypertrophic osteo-arthritis. Diagnosis and treatment. Surg Gynecol Obstet 41:1-14, 1925

24. Rydevik BL, Cohen DB, Kostuik JP: Spine epidural steroids for patients with lumbar spinal stenosis. Spine 22:2313-2317, 1997

25. Sachs B, Fraenkel J: Progressive ankylotic rigidity of the spine (spondylose rhizomélique). J Nerve Ment Dis 27:1-15, 1900

26. Schlesinger PT: Incarceration of the first sacral nerve in a lateral bony recess of the spinal canal as a cause of sciatica. J Bone Joint Surg (Am) 37:115-124, 1955

27. Tuite GF, Stern JD, Doran SE, et al: Outcome after laminectomy for lumbar spinal stenosis Part I: Clinical correlation. J Neurosurg 81:699-706, 1994

28. Turner JA, Ersek M, Herron L, et al: Patient outcomes after lumbar spinal fusion. JAMA 268:907-911, 1992

29. Turner JA, Ersek M, Herron L, et al: Surgery for lumbar spinal stenosis. Attempted meta-analysis of the literature. Spine 17:1-8, 1992

30. Van Itallie TB: Health implications of overweight and obesity in the United States. Ann Intern Med 
103:983-988, 1985

31. Verbiest H: Radicular syndrome from developmental narrowing of the lumbar vertebral canal. J Bone Joint Surg (Br) 26:230-237, 1954

32. Verbiest H: Sur Certaines Formes Rares de Compression de la Queue de Cheval. Hommage à Clovis Vincent. Paris: Maloine, 1949, pp 161-174

33. Von Bechtrew WV: Rigidity and curvature of the vertebral column as a special form of disease. Dtsch Ztschr Nervenheilk 11:327-337, 1892

34. Weinstein JN, Scafuri RL, McNeill TW: The Rush-Presbyterian St. Luke's lumbar spine analysis form: a prospective study of patients with spinal stenosis. Spine 8:891-896, 1983

Manuscript received June 20, 1997.

Accepted in final form February 23, 1998.

This paper was presented at the 9th Annual Meeting of the International Intradiscal Therapy Society, Amsterdam, Holland, May 8-12, 1996; and the Joint Section of Disorders of the Spine and Peripheral Nerves Annual Meeting, Newport Beach, California, February 19-22, 1997.

Address reprint requests to: Manucher J. Javid, M.D., University of Wisconsin Medical School, H4/346 Clinical Science Center, 600 Highland Avenue, Madison, Wisconsin 53792. 